\title{
Juvenile Accountability; The Intake Process
}

\author{
Phillip Neely \\ Department of Criminal Justice, Saint Leo University, Saint Leo, USA
}

\section{Email address:}

Phillip.neely@saintleo.edu

\section{To cite this article:}

Phillip Neely. Juvenile Accountability; The Intake Process. International Journal of Secondary Education. Vol. 5, No. 2, 2017 , pp. 16-21. doi: $10.11648 /$ j.ijsedu.20170502.11

Received: November 23, 2016; Accepted: March 10, 2017; Published: March 21, 2017

\begin{abstract}
In Savannah, Georgia, the juvenile justice system often fails the community and the police department when they do not hold juveniles accountable for their criminal actions. The juvenile intake process creates a problem for law enforcement when they will not accept a juvenile offender due to certain criteria. The juvenile offender is often aware of the process and knows that the Regional Youth Detention Center will not hold them. The inadequate intake process leaves officers to continuously deal with the same repeat offenders, along with having to release the juvenile offenders to their parents because they do not meet certain detention criteria. The issues surrounding the juvenile intake process in Savannah, Georgia is not caused by one particular factor, but by several aspects that are all related. By addressing the aspects involved, it will allow one to have a better understanding of the problem. The factors surrounding this problem keep juvenile offenders on the street instead of in jail. The Georgia Juvenile Justice Reform System wants to save the state millions of dollars by keeping fewer offenders incarcerated in state run facilities. This will allow juvenile offenders to be released back into the community. The change in the juvenile justice system through the 2013 reform costs affects the detainment of juvenile offender.
\end{abstract}

Keywords: Juvenile Justice Reform. Delinquent, Rehabilitation, Intake Process

\section{Introduction}

The juvenile court judge is also limited on the ability to order a delinquent youth to home placement and or a group home. The topic concerning modern technology in the juvenile justice system is often utilized to lower costs of housed juvenile offenders. Juveniles are placed on electronic monitor devices to keep up with their movements. In Savannah, Georgia before juvenile offenders can be accepted into the Regional Youth Detention Center one must meet certain criteria. The Chatham County Juvenile Intake officers utilize a point system that determines if the offender will be detained. The method in which the point system is calculated often ends with law enforcement returning the juvenile offender back to their parents. The political influence of the juvenile justice system can create an adversarial environment with the public. The 2014 reform cost for juvenile detention centers are an outcome of political influence to lower the government's spending. The Savannah Regional Youth Detention Center is currently at capacity as the crimes being committed by juveniles' rise. The intake officers are seeking other placement to cut costs. It cost the state almost 100,000 dollars a year to house a juvenile offender.

While people ranging across the age spectrum can commit crime, one has to consider that there are different methods of detention when dealing with adult offenders as opposed to the juvenile offenders. According to The Office of Juvenile Justice and Delinquency prevention, (OJJDP) theft is shown as the greatest cause of youth arrest. The realism of juvenile delinquency is made up of numerous mechanisms of societal styles. In the midst of these is a drop in available jobs which results in loss of wages. A likely connection may occur because juveniles frequently look for unlawful means to aid in taking care of their loved ones (Siegal \& Welsh, 2012).

Criminal behavior is greater in the metropolitan regions and is much lower in the country areas. Violent crime is a severe issue in Savannah-Chatham County. Most acts of criminal activity occur during summer vacation, as juveniles have a better chance throughout the summer to take part in criminal activity. The hotter it becomes the more unruly juveniles turn out to be (Siegal \& Welsh, 2012). Juveniles are heavily involved in both vicious and weapon connected misconducts, as offenders and victims. Contact with great levels of violence disturbs the juvenile's societal and emotional growth. 
According to Siegel \& Welsh (2012), the use of rational conduct rehabilitation displays an unparalleled decrease in juveniles reoffending even amongst high-risk delinquents. The rational conduct rehabilitation platform was over 400 experimental trials linking a wide assortment of circumstances and residents. The platform has remained dependable and operative, with an extensive variation of conduct issues. These issues are disruptive and violent in nature, all of which have remained connected to criminal behavior amongst juveniles (Siegel \& Welsh, 2012). The degree of the issue is to restructure those juveniles who are dealing with trials related to behavior difficulties that will ultimately turn them to criminal activity therefore living a life of crime.

There are numerous youth services all over the world however, in the state of Georgia the juvenile crime is so grave, they are detained in facilities with adults. In the state of Georgia once juveniles turn 17, they are no longer housed in youth detention centers as they are considered adults. In 1994, state legislators strengthened juvenile justice regulations by reinforcing punishments of most violent crimes and they began by sending juveniles to adult jails (Territo, Halsted, \& Brombley, 2004). Yet, policymakers have also given courts the option to keep some of the severe offenses that are committed by juvenile offender in the state's juvenile facilities (Walls, 2014). The minimum age of juvenile courts has widespread variations all over the world, and the placement of this age is fixed on inquiries about a child's capability as well as the policy of best interests of the child. An additional problem that must be taken into consideration is the question of whether or not the format of the official criminal court is the most suitable means of mediation with children and youths when they take part in acts that might be considered illegal (Chambliss, 2011).

\section{Literature Review}

The original juvenile court in the United States was originated in Chicago in 1899, greater than 100 years ago. Throughout the last 30 years, the juvenile justice association has weathered significant modifications. Perceptions of a juvenile delinquency outbreak in the early 1990s fueled public scrutiny of the administration's competence to manage vicious juvenile offenders (Territo, Halsted, \& Brombley, 2004). According to Swanson, Territo, \& Taylor (2008), states have applied numerous governmental alterations in a struggle to attempt to stop juvenile misconduct. Any juveniles who were in violation of the regulation were named "juvenile delinquents" not criminals, this inferred to the teens that were unruly youths that required aid from the court.

According to Territo, Halsted, \& Brombley (2004), the juvenile court judges were to adopt a parent role in an atmosphere that is less threating than that of a grownup atmosphere. As an outcome, criminal magistrates evaluated the conduct of juveniles, punishing them when suitable, and formulating a path of progression to avert upcoming criminal conduct. In addition, the court employed a therapist and social workers to formulate wide-ranging studies on the juveniles' background.

The Georgia Juvenile Justice Reform Act of 2013, comparable to the restructuring of adult penalizing and corrections, was placed into action in January 2014. This act was applied to place juveniles who are not extremely dangerous back into the public. The reform act will offer judges more freedom in juvenile case sentencing, provides more medication and psychological wellbeing therapy; and place more stress on local community established outreach platforms, rather than confinement to detention facilities for non-violent juvenile delinquents. Georgia presently spends more than ninety thousand dollars a year for each juvenile criminal held in custody and $65 \%$ of those lawbreakers end up back in confinement in 3 years after their discharge. Georgia's present Juvenile Code has stood in effect in Georgia since the 70's. Supporters feel the wide-ranging transformations endorsed today by the overall assembly are anticipated to generate 28 million dollars in savings for the State of Georgia throughout the next two years alone (Howard, 2013). This reform is directed at altering a state conventionally hard on law-breaking into one that saves expensive juvenile detention bed space for the greatest violent lawbreakers, while decreasing reoffending through communal created substitutions (Howard, 2013). The reform act offered a 5-million-dollar Juvenile Justice allowance. This allowance grants counties up to $\$ 500,000$ for evidence centered alternate platforms that decrease juvenile reoffending (Howard, 2013).

Lawyer and state representative Mary Oliver advised that, the Department of Juvenile Justice recidivism averages are unacceptable and its obvious policymakers are both wasting citizen's money and are not helping young criminals nor safeguarding the public. Recidivism is described as those delinquents who after three years of being discharged from detention committed another felony, to which they were consequently, sentenced (Walls, 2004).

According to Judge Patricia Stone, Chatham County Juvenile Court governing judge, expansions in expenditures are anticipated, nevertheless, the transformations could also be important when the time came to apply the new reform rules. The reform of Georgia's juvenile justice system is anticipated to save the state millions by detaining fewer lawbreakers in state- run facilities. Unfortunately, Chatham County may see its juvenile court budget increase (Howard, 2013).

The Georgia Juvenile Justice Reform Act restricts the quantity of time that those juveniles can essentially stay in detention due to a two-class structure that defines felony transgressions. They are broken down into class A for graver felonies and Class B for felonies with explanatory conditions, such as drug possession not linking the selling, production, or distribution of prohibited drugs. Juveniles sentenced of a class "A crime will be qualified to obtain a maximum of 60 months in detention at a youth detention facility, while class $\mathrm{B}$ crimes will end in up to 36 months of detention, with just half the punishment obligated to be served in a juvenile 
detention facility. The new reform ruling lifts any restrictions judges had in penalizing juveniles (Howard, 2013).

In 1974, Congress applied a bill now identified as the Juvenile Justice Delinquency Prevention (JJDP), inside the Department of Justice. The bureau administers allowances to the states and regions in order to offer mechanical support, to aid the authorities with staying in agreement with the act's provision (Territo, Halsted, and Brombley, 2004). The platform of the act orders that contributing states eliminate status criminals such as- runaways, truancy violators, and non- offenders that are mistreated and neglected youths from juvenile detentions and correctional facilities. Nevertheless, in 1980, the act was revised to demand that the state eliminates all juveniles from adult facilities (Territo, et al., 2004).

In addition, the Georgia Reform Act prevents Georgia youth from being involuntarily detained up for status offense violations. Crimes such as running away, school truancy, or curfew violations are named status offenses since they are centered merely on juvenile standing. Under the Georgia Juvenile Justice Reform Act of 2013, juveniles formerly referred to as "unruly children" who commit these kinds of wrongdoings are now considered to be "Children in Need of Services". This rule permits police officers, the Department of Juveniles Justice, and the Division of Family and Children Services to acquire healing and service strategies for those juvenile delinquents, rather than instantly referring them to youth detention facilities (Howard, 2013).

Essentially, diminishing reoffending by youth before the juvenile court must remain to be the initial objective of delinquency procedures. For instance, the dispositional mediation should be devised primarily to "fit the offender" (McGarrell, 1988). Together, nevertheless, the juvenile justice organization should also guarantee that juveniles are held responsible for their misconduct and that, in doing so, they are treated impartially. An analysis of modern juvenile justice statutes discloses that they usually affirm double goals: holding youth responsible and offering rehabilitative amenities to diminish their possibility of recidivism. Both of these objectives are essential to please community expectancies that counteractive action will be taken. In societies vision, both of these objectives can and must be strongly secured in a growing tactic to juvenile transgressing (McGarrell, 1988).

Liability exercises in juvenile justice should be intended particularly for juvenile justice rather than being conveyed over from the criminal courts and should be proposed to endorse fit social knowledge, ethical growth, and lawful socialization throughout youth. If planned and applied in a developmentally knowledgeable method, practices for holding juveniles responsible for their criminal wrongdoing can endorse constructive lawful socialization, support a prosocial individuality, and enable obedience with the law. Nonetheless, excessively punitive mediations and adverse communications amongst juveniles and the justice system administrators can weaken reverence for the law and legal power and emphasize a divergent individuality and community alienation (McGarrell, 1988).

\section{Finding}

The State of Georgia applied deterrence platforms to help decrease delinquency and to reorient those persons who have been victims of a misconduct. The programs were also to assist in solving the problem of delinquency and violence inside the state (Brooks, 2013). The criminal justice organization is creating a broad range of exercises of management and organizations that establish and uphold the public surroundings. Preventing and lessening the occurrences of criminal activities complete this. Nonetheless, the model responsibility of a criminal justice administrator is to impose legal matters, which incorporates imposing trial processes to criminals, penalizing of criminals, protection and hearing confinement, and managing those who have took part in a criminal act and/or have dishonored state guidelines or protocols (Brooks, 2013).

The Savannah Impact Program applied electronic monitors that juveniles wear on their legs, permitting them to leave home when scheduled. Any deviation is automatically transmitted electronically to the probation or intake officer. SIP has 22 monitors available for juvenile offenders who have been released. The Chatham County Juvenile Court has about 60 monitors, however, there are not enough probation officers devoted to monitor the juvenile's activities. The leg monitors are supervised at night for tamper alerts and dead batteries. During after hour periods juveniles have been known to cut the leg monitors off their legs (M. Routh, 2015).

According to Routh (2015), The Savannah Chatham Juvenile Court has applied two platforms for therapy such as Aggression Replacement Therapy (ART) and Functional Family Therapy (FFT). Aggression Replacement Therapy is a mediation developed for hurtful juveniles and children. Its essential procedures are Skill Streaming, which explains a platform of Pro-Social, social skills, and Anger Control Training, to educate juveniles on what not to do if encouraged. Last, Moral Reasoning Training is used to validate principles that respect the truths of others, and assists juveniles who want to use the social and anger management skills explained.

Functional Family Therapy is a temporary family therapy intervention and juvenile alteration platform helping at-risk children and delinquent juveniles to overcome youthful behavior matters, conduct disorder, substance abuse and disobedience. Therapists work with families to assess family behaviors that endorse criminal behavior, modify dysfunctional family collaboration, train family members to bargain efficiently, set unblemished rules about rights and responsibilities, and simplify changes to community locations and communications (Routh, 2015).

The Savannah Impact Program (SIP) is an expert unit inside the Savannah-Chatham Metropolitan Police Department (SCMPD), functioning as a Community Reentry Collaborative, mainly concentrating on "high risk" and "at 
risk" youth and adults. The SIP collaborative is made up of sworn and civilian police employees as well as various community management organizations to consist of the Georgia Department of Corrections, Board of Pardons and Parole, Chatham County Juvenile Court and the Department of Juvenile Justice. The objective of the Savannah Impact Program is to diminish reoffending committed by high-risk delinquents who are overseen by the Savannah Impact Program (Flynn, 2003).

According to Flynn (2003), the Savannah Pre-Apprentice Program is a program that will instill life abilities and academics to a collection of about 40 partakers, extending from the age of 14-18. The Chatham County Juvenile Court and Department of Juvenile Justice have suggested these applicants. The platform also will offer on-the-job training with the City of Savannah and area businesses. Front-runners from the faith-based community will assist, as advisors to the applicants, made up of low-risk, non-violent delinquents.

Throughout the program, participants obtain mathematics and English tutoring from expert instructors, which is trailed with an assessment to gage scholastic improvements. The life-skills element consists of instruction in disagreement resolution, time managing, guidance, individual health and wellness, monetary managing and job readiness (Curl, 2015).

The importance of juvenile selection, evaluation, and recommendation has been intensely enhanced in the previous few years mainly in connection to psychological well-being and substance abuse issues amongst adolescent criminals. However, as one present evaluation discovered, value and in depth assessments of youths entering the juvenile system remains the exclusion rather than the rule (Dembo \& Brown 1994, p.29). The explanation of the reasons of evaluations takes on extra importance when one contemplates that there is a rising importance on managing official hazard and necessities evaluations at the earliest phases of a juvenile justice procedure. The huge majority of casually and officially managed juveniles eventually have their cases discharged, are deterred from the juvenile justice system, or accept probation, and that the current juvenile justice reforms have significantly extended evidence collecting and distribution amongst numerous local and state organizations (Mears \& Kelly, 1999).

Youths who enter the juvenile justice system are primarily processed through intake. Although 80 to 90 percent of all recommendations come from law enforcement organizations, a moderately minor fraction comes from additional sources to include educational facilities and parents (Mears \& Kelly, 1999). Each authority utilizes lawful standards to establish which youths should be held in secure locations. These normally depend if the juvenile is a threat to the well being of the public, if the juvenile has insufficient guidance from a parent or caretaker at home, and if the juvenile is considered a flight hazard from the jurisdiction. If any of these circumstances are considered to be present, the child may be placed in secure detention (Chambliss, 2011). There are a number of phases in managing juvenile offenders pre-arrest, apprehension, intake, custody adjudication, and disposition.
Nevertheless, a huge majority of juveniles are not imprisoned, adjudicated, or set a disposition. Most juveniles have their incidents discharged or accept informal sanction agreed upon through the plea agreement between defense lawyers and District Attorneys normally with references from probation (Mears \& Kelly, 1999).

According to Chambliss (2011), each state utilizes legal principles to decide which juveniles should be detained in a secure institutional setting, and is comparable amongst states throughout the country. In the majority of jurisdictions, three vital circumstances are repeatedly used to decide if secure detention is needed. First, and most significantly, the security of the juvenile and the public must be considered. If the juvenile is a danger to community security, for instance, imposing injury to community citizens, has a preceding criminal record (both violent and nonviolent), or if he or she is more likely to be held in a secure detention facility. Second, if a child has insufficient guidance from his or her parents or caretaker, or is of mistreated or contingent standing, he or she is more likely to be detained in a secure location. Third, if the juvenile is thought to be a flight risk from authority and likely not to appear in court for adjudication, disposition, and or program assignment, he or she is likely to be placed in a secure location (Chambliss, 2011).

\section{Recommendations}

Intake is normally designed differently throughout jurisdictions and intake officers can normally utilize significant discretion in how incidents are handled. The Chatham County juvenile intake procedure starts when a resident makes a complaint to the Juvenile Court implicating a suspected delinquent or unruly deed by a juvenile. The juvenile is either discharged to their parents or held in the detention center to await a hearing. The juvenile complaint is given to an intake employee to decide the proper course of action. Juvenile complaints are controlled one in four methods (Chambliss, 2011).

First, the complaint is handled by formal action, which involves planning the matter for a hearing $\mathrm{n}$ front of a judge. Due to the often prolonged delay between the arrest and the adjudication trials, a serious choice must be made to either discharge the youth under arrest to the supervision of a parent or qualified caretaker, or hold the juvenile, resulting in the assignment of the juvenile in the care of the state (Chambliss, 2011).

The second technique is an informal modification, which is a deviation from the court trial. The intake officer sets circumstances that need to be met if the complaint is handled officially. The intake worker exercising his or her own discretion typically chooses whether to handle the case casually. The deviation in intake and the discretion given to intake officers is in agreement with the "parens patriae" spirit of the original juvenile court, to include the impact on nonadversarial actions and adaptable decision-making (Mears \& Kelly, 1999).

Yet, despite the significance of intake to decision making 
about juveniles, most investigation has concentrated on post intake processing, mainly incarceration and official processing, even though most juveniles are never held, officially processed, or relinquished to adult court. Given the potential for intake to impact all consequent processing, it establishes one of the most vital points in the whole juvenile justice procedure for employing deterrence or early mediation tactics or both, it rests as a generally under explored feature of juvenile processing (Mears \&Kelly, 1999). The third manner to handle a juvenile complaint is by discharging the complaint. A complaint may be discharged for several purposes; nevertheless, the most shared reason is due to insufficient probable cause. If a complaint does not contain adequate evidence for prosecution, the Assistant District Attorney can make a demand to law enforcement to give an investigator the case for further review. The fourth method is by removing the complaint. The complainant can remove a complaint. The complainant is usually the victim or the parent of the assumed victim. This means the complainant does not desire to pursue the matter any more. The complainant must go to Juvenile Court and sign a "withdrawal" (Howard, 2013).

According to Routh (2015), the Chatham County Juvenile Court, located in Savannah, Georgia utilizes a Detention Assessment Instrument (DAI) to determine if a juvenile should be detained into the detention center. This tool calculates points in reference to the crimes committed by the juvenile. For example, a juvenile who commits a crime such as robbery and aggravated assault, with no prior arrest history will automatically score 12 points, allowing the intake officer on duty to authorize the juvenile to be housed in the detention center. This assessment tool also takes into account whether the juvenile has been on probation, case adjudication, previous arrest histories and failure to appear. Law enforcement officers often face the challenge of having to find other placement for juveniles who are not accepted into the Chatham County Regional Youth Detention Center. The intake officer is required to offer alternate options such as Greenbrier and Park Place Outreach, which are both alternate rehabilitation platforms and group homes. This can become an obstacle if the centers are full or if the juvenile displays violence (Routh, 2015).

Juveniles who have been adjudicated and are expecting assignment/transfer to a residential commitment program may be held by the state as well. This procedure of placing the juvenile in detention after arrest and/or before transfer to a commitment facility is known as detention. Detention can take many forms, such as assignment in a secure location. Normally, a juvenile detention facility actually looks like a jail and/or prison for adults (Chambliss, 2011).

\section{Conclusion}

The Savannah Regional Youth Detention Center (RYDC) offers short-term, protected care and observation to juveniles who are accused of offenses or who have been found responsible for crimes and are awaiting disposition of their cases by a juvenile court. Though, secure confinement is presently undergoing numerous issues, to include overpopulation, physical plant corrosion, and a lack of programming, for instance, substance abuse reduction or education, that incarcerated juveniles may require. Furthermore, juveniles committed to the care of the Department of Juvenile Justice (DJJ) are frequently detained in secure detention facilities while awaiting assignment in one of DJJ's treatment programs or facilities (Chambliss, 2011).

RYDC strives to provide education, separate leadership and therapy, medical amenities, recreation, and arts and crafts. Clothing, meals, medical, and emergency dental care are a part of this center's basic care program. The 100-bed facility is at capacity; however, it has begun to experience relief (Routh, 2015).

Official measures of crime are made up of police and court archives, such as arrest statistics. Statistics can be collected to gage delinquency for a certain population, such as participants in mediation, or they can be gathered across a community or even nationwide. One frequently cited source is the Uniform Crime Reports (UCR). The UCR's have been composed from local law enforcement agencies and recorded by the Federal Bureau of Investigation since 1929. The UCR contains facts on known crimes and apprehensions (Redding, Goldstein, \& Heilbrun, 2005).

In 2009, Chatham County Juvenile Court received 4, 805 referrals as 2,832 juveniles younger than 17 passed through the system on a total of 6,101 charges. In 2012, the court received 2,834 referrals linking 2,103 juveniles and 4,045 charges, according to court facts (Howard, 2013).

"The majority of the referrals in 2012 came from the Savannah-Chatham Metropolitan Police Department (952), followed by the state Division of Family and Children Services (439) and Savannah-Chatham Public Schools (406), according to annual reports. Of the 3,186 delinquent and unruly charges referred to the court in 2012, a combined 62 percent of all referrals, where the most frequent were violation of probation (225), ungovernable (198), theft by shoplifting (192), criminal trespass (165) and contempt of court (164)" (Howard, 2013).

The physical, rational, social, and emotional aptitudes of juveniles and teenagers are constantly progressing. It is this continual and constant transformation, as well as diverse weaknesses, that separate juveniles from adults (Redding, Goldstein, Heilbrun, 2005).

Forensic therapists and others assessing youth in the juvenile justice system should evaluate these capabilities since they are most applicable to psychosocial responsibility; they should not merely link these capabilities from other characteristics or aspects that essentially may not be connected (Redding, et al., 2005).

Since the juvenile court wants to focus on rehabilitation rather than punishment, lawful defenses were considered to be neither appropriate nor required. Consequently, in juvenile court, the rights to legal representation granted under the Sixth Amendment and due process protection granted under the Fourteenth Amendment were traditionally not available 
to youth. Although juveniles were provided many of the same constitutional protections afforded adults, infrequently was attention paid to or concern expressed about whether a specific juvenile actually met the required legal competence constructs (Redding, Goldstein, Heilbrun, 2005). Getting the evidences straight about juvenile offending is a vital foundation to conveying intellectual and operational tactics to avert juvenile delinquency and to create proper power and conduct schedules. The relative powers and disadvantages of study founded on official arrest facts and on juvenile selfreport data are evaluated (Redding, et al., 2005).

According to Saminsky (2010), community-based crime deterrence platforms include those that work inside the community and include neighborhood citizens energetically operating with their local command organizations to address problems adding to corruption, delinquency, and chaos. Civic supporters are encouraged to play vital roles in problem identification and planning resolutions to issues in their neighborhoods. Community residents, law enforcement, and faith-based groups run community-based crime deterrence platforms.

It seems that the juvenile justice organization and chief leaders are joining their assets, in a determination to find resolutions for juvenile misconduct. Deterrence programs can affect the community because they stop the crime from occurring. The characteristic of an effective platform is their all-inclusive environment, and if the platform is general, it concentrates on the numerous features of a juvenile's life. (Saminsky, 2010).

A single noteworthy structure for categorizing public risk entities is: differentiating public structure, oppositional ethnicity, public configuration and social and physical disorder. Each of these entities could be the emphasis of wide-ranging community crime deterrence platforms (Sherman, 1997). Communities have been the central institution for crime prevention. They have also been the attention on which all other institutions joined together with families, schools, stores, law enforcement and corrections. These community leaders must all face the consequences of public life (Sherman, 1997). Community deterrence platforms have been inspired by local public front-runners to plan and apply their individual crime deterrence tactics (Sherman, 1997).

While new approaches have been applied to alleviating the wrongdoings that are committed by adolescence, backers must show interest in the result of juvenile programs. In order for deviation platforms and community discharge platforms to work effectively, guidelines and techniques made by politicians and their official backers will need to be amended, to ensure that when youth attend deterrence programs this action is documented in order to endorse their involvement and willingness to be released back into the community. It is also vital to note when juveniles disobey the policies, so that the retribution fits the act. If there is no severe accountability imposed for juveniles when they commit a crime, then the program is defeating the purpose of reducing the re-entry back into the juvenile justice system.

\section{Author Information}

Dr. Phillip Neely is the recipient of the Doctor of Philosophy in Public Policy and Administration with a specialization in Criminal and the Masters of Science in Public Administration/Criminal Justice. He is an Associate Professor at Saint Leo University in Duluth, Georgia. Dr. Neely's expertise comes in the field of criminal justice and public policy.

\section{References}

[1] Brooks, J. (2013). Preventing crime and violence. Crime and Delinquency, 20 (3), 241-244.

[2] Chambliss, W. J., \& Sage Publications. (2011). Juvenile crime and justice (5th ed.). Thousand Oaks, CA: SAGE.

[3] Curl, E. (2015, May 5). Savannah youth program aims to curb juvenile arrests. Retrieved from http://www.savannahnow.com

[4] DeList, M., \& Conis, J., P. (2012). Violent Offenders. Theory, Research, Policy, and Practice. ( $2^{\text {nd }}$ edition). Jones and Barlett Learning. LLC.

[5] Flynn, D. (2003) Savannah Impact Program. Excellence in Problem-Oriented Policing.

[6] Heilbrun, K., Goldstein, N. E., \& Redding, R. E. (2005). Juvenile delinquency: Prevention, assessment, and intervention. New York: Oxford University Press.

[7] Howard, M. (2013, June 16). Chatham County braces for juvenile justice reform costs.

[8] McGarrell, E. F. (1988). Juvenile correctional reform: Two decades of policy and procedural change. Albany, NY: State University of New York Press.

[9] Mears, D. P., \& Kelly, W. R. (1999). Assessments and intake processes in juvenile justice

[10] Routh, M. (2015, May 26). Savannah Impact Program Juvenile Court Supervisor. (S. Badie, Interviewer)

[11] Saminsky, A. (2010). "Preventing Juvenile Delinquency: Early Intervention and Comprehensiveness as Critical Factors." Student Pulse, 2 (02). Retrieved From http://www.studentpulse.com/a?id=165

[12] Sherman, L. W. (1993). Defiance, deterrence, and irrelevance: A theory of the criminal sanction. Research in Crime and Delinquency, 30 (4), 445-473.

[13] Siegel, J. L., \& Welsh, C. B. (2012). Juvenile Delinquency Theory Practice And Law. Wadsworth Cengage Learning.

[14] Swanson, R. C., Territo, L., \& Taylor, W. T (2008). Police Administration Structures Processes and Behavior $\left(7^{\text {th }}\right.$ edition). Pearson Education Incorporation. Upper Saddle River New Jersey.

[15] Territo, L., Halsted, B. J., \& Brombley, L. M. (2004). Crime and justice in America. A human

[16] Perspective. (6th ed.). Upper Saddle River, NJ. Walls, J. (2004). Georgia's troubled effort to reduce juvenile crime. 